\title{
Motility and biofilm production involved in the interaction of phosphate solubilizing endophytic strains with peanut, maize and soybean plants
}

\author{
Cinthia Tamara Lucero ${ }^{\text {a,c }}$, Graciela Susana Lorda ${ }^{a}$, Liliana Mercedes Ludueña ${ }^{\text {b,c }}$, \\ María Soledad Anzuay ${ }^{\text {b,c }}$, Tania Taurian ${ }^{\text {b,c,* }}$ \\ ${ }^{a}$ Departamento de Química, Facultad de Ciencias Exactas y Naturales, Universidad Nacional de La Pampa. Ruta Nacional 35 Km 330 , Santa Rosa, CP 6300, Provincia \\ de La Pampa, Argentina \\ ${ }^{\mathrm{b}}$ Departamento de Ciencias Naturales, Facultad de Ciencias Exactas, Físico-Químicas y Naturales, Universidad Nacional de Río Cuarto, Agencia Postal 3, 5800, Río \\ Cuarto, Córdoba, Argentina

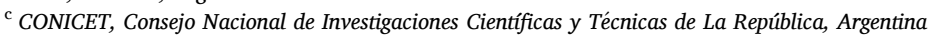

\section{A R T I C L E I N F O}

\section{Keywords:}

Endophytic bacteria

Swarming

Swimming

Twitching

Index biofilm formation

Root exudates

\begin{abstract}
A B S T R A C T
Endophytic plant growth promoting bacteria are of great interest since the ability to colonize the internal tissues of plants gives it an adaptive advantage. To confer any beneficial effect on the plant, bacteria must present a successful colonization and thus be competent in the rhizosphere and finally infect internal tissues. In this sense, bacterial motility is an essential property involved in plant-microorganism interaction where bacteria can colonize the root and at the same time form biofilms. Within plant beneficial bacteria those that present phosphate solubilizing activity are of great interest due to the contribution of phosphorus to plants. The objective of this work was to evaluate the motility and biofilm formation properties of the strains Serratia sp. S119 and Enterobacter sp. J49 growing in the presence of peanut, maize and soybean root exudates. Results obtained indicated that both strains have flagella, possess swimming, swarming and twitching motilities and showed differential chemotactic attraction against root exudates. In addition, the strains under study showed the ability to form biofilms, being this ability greater in minimal media, in which a greater decrease was also seen by the addition of root exudates in the first hours of growth. The changes produced by the addition of root exudates in the chemotaxis and biofilm formation of the strains suggests that compounds released by the plants are detected by these bacteria and could be part of the molecular dialogue involved in their interaction with the roots of plant.
\end{abstract}

\section{Introduction}

Plants and their associated microorganisms, which can be rhizospheric, epiphytic and endophytic, are characterized by varied and complex interactions and have been the subject of extensive research and various applications (Glick, 2012). These microorganisms can be classified according to their effect on plants and the way they interact with them. Thus, some are pathogenic, while others trigger beneficial effects (Saharan and Nehra, 2011). Bacteria that promote plant growth are known as "Plant Growth Promoting Bacteria" (PGPB) (Bashan and Holguin, 1998). They are defined as those that, in the soil, the rhizosphere, the rhizoplane, the phyllosphere and/or within the plant tissue, under certain conditions, are beneficial for the plants. Within PGPBs are insoluble phosphate solubilizing and/or mineralizing bacteria (PSB). They constitute an important group in the natural cycle of phosphorus
(P), mainly due to the contribution of this nutrient to plants. The mechanism of solubilization of inorganic phosphate compounds by PSB is generally associated with the release of low molecular weight organic acids, which through their hydroxyl and carboxyl group, chelate the cations $\left(\mathrm{Al}^{3+}, \mathrm{Fe}^{2+/ 3+}\right.$ and $\mathrm{Ca}^{2+}$ ) linked to phosphates making them soluble (Behera et al., 2014). On the other hand, generally the mineralization of organic compounds of $\mathrm{P}$ is carried out by enzymatic mechanisms through the production of enzymes such as phosphatases (phosphohydrolases) or phytases (Behera et al., 2014; Rodríguez et al., 2006).

Within PGPB, endophytic microorganisms are of great interest since it is considered that the ability to colonize the internal tissues of plants gives to the bacteria an adaptive advantage (Hardoim et al., 2008). Before being able to confer any beneficial effect on the plant, endophytic PGPBs must accomplish a successful colonization in the rhizospere. For

\footnotetext{
* Corresponding author. Universidad Nacional de Río Cuarto, Ruta 36 km 601, 5800, Rio Cuarto, Córdoba, Argentina.

E-mail address: ttaurian@exa.unrc.edu.ar (T. Taurian).
} 
this, they need to be competent in the rhizosphere and/or rhizoplane (Whipps, 2001) and finally infect internal tissues. Both rhizospheric and rhizoplane colonization are intimately linked to exudates released by the roots. Compounds released by the roots are carbohydrates, amino acids, organic acids, which constitute a source of nutrients for soil bacteria (Zhalnina et al., 2018). Root exudates produce variable patterns of molecules along the root, making bacterial colonization not uniform (Hayat et al., 2017).

It has been described that the infection of internal tissues by endophytic bacteria would involve specific characteristics such as the ability to produce enzymes degrading plant cell walls, detoxification mechanisms, twitching or flagellate-mediated motility, lipopolysaccharide production and, in the specific case of rhizobia, nod genes (Compant et al., 2010). Nevertheless, in some cases endophytic colonization occurs passively through fissures that occur in emerging roots, created by pathogenic microorganisms or at the tip of the root (apical meristem) (Reinhold-Hurek and Hurek, 2011). In the fight for survival, the ability to colonize different environments can provide new resources and opportunities to bacteria. Bacterial motility towards root exudates plays an important role in the colonization of the rhizosphere and the rhizoplane (Lugtenberg and Kamilova, 2009). Swimming, swarming and twitching they are within the most studied motilities (Harshey, 2003). Swarming and swimming motility are a mode of bacterial movement that is propelled by rotating flagella. Twitching motility is produced on surface driven by the extension, adhesion to the surface and retraction of the type IV pili by pulling the cell towards the junction site (Jarrell and McBride, 2008).

In addition to motility, chemotaxis, which is the response to chemical agents, allows bacteria, among other things, to search for nutrients and transport themselves effectively to grow and survive (Mazumder et al., 1999). It has been studied in detail in flagellated bacteria, although some without flagella are also chemotactic (Lux and Shi, 2004). Swimming motility is known as the fundamental basis of the process denominate as chemotaxis (Lux and Shi, 2004). Another aspect linked to bacterial colonization in its interaction with plants, is the ability to produce biofilm. This bacterial structure gives competitive advantages as it allows to survive desiccation and other types of environmental stress (Molina et al., 2003), leading to efficient colonization of the interior of the plant. Thus, biofilm constitute a protected mode of growth and development, being their behaviour and physiology significantly different from those microorganisms that grow free in the environment (Costerton et al., 1999). Bacteria that reside in the biofilm matrix are protected from various environmental stress factors, such as extreme $\mathrm{pH}$, UV radiation, antimicrobial substances, dehydration and osmotic shock, and presence of predators (Romanova et al., 2006; Costerton et al., 1987).

PSB constitute a biotechnological tool for the improvement of agricultural crops yield- Thus the study of mechanisms involved in their interaction with plant is an important aspect to explore. Considering, that endophytic colonization is a desirable trait when looking for a potential inoculant, it is important to inquire about all the steps involved in this process.

Strains used in this study are two efficient phosphate solubilizers (Taurian et al., 2010) that promote the growth of peanut, maize (Anzuay et al., 2013, 2017; Ludueña et al., 2017), and soybean (data no shown). Given the promising effects produced by the inoculation of these strains, further studies were attempted to gain more knowledge in the mechanisms of the interaction between beneficial endophytic bacteria and agronomical important plants, especially those related to bacterial infectivity. This work was based on the hypothesis that in beneficial non-symbiotic bacteria, the mechanisms involved to enter the host plant involve more than one type of motility and the ability to produce biofilm and that root exudates influence on them. In this regard, the objective of this study was to evaluate the motility and biofilm formation properties of the Serratia sp. S119 and Enterobacter sp. J49, growing in the presence of peanut, maize and soybean root exudates.

\section{Materials and methods}

\subsection{Bacterial strains, media and growth conditions}

Strains used were Serratia sp. S119 and Enterobacter sp. J49 (Taurian et al., 2010). Selection of these strain was based on their ability to efficiently solubilize phosphate in vitro and on its ability to promote the growth of peanut (Anzuay et al., 2013, 2017), maize (Ludueña et al., 2017) and soybean plants (unpublished data). Bacteria were grown on LB (Tryptone $10 \mathrm{~g} \mathrm{l}^{-1}$, yeast extract $5 \mathrm{~g} \mathrm{l}^{-1}$, NaCl $5 \mathrm{~g} \mathrm{l}^{-1}$, Miller, 1972); TY (Tryptone $5 \mathrm{~g} \mathrm{l}^{-1}$; yeast extract $3 \mathrm{~g} \mathrm{l}^{-1}$; $\mathrm{CaCl}_{2} \cdot 6 \mathrm{H}_{2} \mathrm{O} 1.3 \mathrm{~g} \mathrm{l}^{-1}$; Beringer, 1974); NBRIP (glucose $10 \mathrm{~g} \mathrm{l}^{-1} ; \mathrm{Ca}_{3}\left(\mathrm{PO}_{4}\right)_{2} 5 \mathrm{~g} \mathrm{l}^{-1}$;

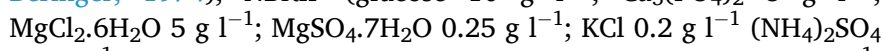
$0.1 \mathrm{~g} \mathrm{l}^{-1}$; Mehta and Nautiyal, 2001); and NBRIP-Psol (glucose $10 \mathrm{~g} \mathrm{l}^{-1}$; $\mathrm{KH}_{2} \mathrm{PO}_{4} 3 \mathrm{~g} \mathrm{l}^{-1} ; \mathrm{MgCl}_{2} .6 \mathrm{H}_{2} \mathrm{O} 5 \mathrm{~g} \mathrm{l}^{-1} ; \mathrm{MgSO}_{4} .7 \mathrm{H}_{2} \mathrm{O} 0.25 \mathrm{~g} \mathrm{l}^{-1} ; \mathrm{KCl} 0.2 \mathrm{~g}$ $\left.\mathrm{l}^{-1} ;\left(\mathrm{NH}_{4}\right)_{2} \mathrm{SO}_{4} 0.1 \mathrm{~g} \mathrm{l}^{-1}\right)$ media and maintained in $20 \%$ glycerol $\left({\left.\mathrm{v} . \mathrm{v}^{-1}\right)}^{-1}\right.$ at $-80^{\circ} \mathrm{C}$. For the determination of the grow generation time $3 \mathrm{~mL}$ of an inoculum in LB medium of each bacteria (approximately $10^{9} \mathrm{CFU} \mathrm{ml}{ }^{-1}$ ) were transferred to $60 \mathrm{ml}$ of $\mathrm{LB}$ medium and were grown at $28^{\circ} \mathrm{C}$, with $200 \mathrm{rpm}$ of agitation. Samples were taken every $2 \mathrm{~h}$ and at each incubation time, CFU. $\mathrm{ml}^{-1}$ by microdrop plate method (Somasegaran and Hoben, 1994) in LB medium was determined. This assay was performed three times independently, with a six replicates each one.

\subsection{Phosphate solubilizing capacity}

One ml aliquot $\left(\mathrm{OD}_{660 \mathrm{~nm}}=0.3\right)$ of an overnight culture of each bacterium grown in LB medium was transferred to an Erlenmeyer containing $60 \mathrm{ml}$ of NBRIP medium. Cultures were incubated at $28^{\circ} \mathrm{C}$ with agitation (200 rpm). At 24, 48, 72, 96, 120, 144 and $196 \mathrm{~h}$ a $1 \mathrm{ml}$ aliquot was aseptically taken to quantify the $\mathrm{P}$ solubilized by the bacteria. The aliquot was centrifuged at $10,000 \mathrm{rpm}$ for $12 \mathrm{~min}$ to settle the bacteria and the insoluble P. Soluble P was determined in the supernatant by the colorimetric technique of Fiske and Subbarow (1925) adapted to small volumes. This assay was performed two times independently, with eight replicates each one.

\subsection{Motility assays}

Swimming, swarming and twitching motilities were determined. For swimming and swarming motilities the methodology described by Nievas et al. (2012) of the strains under study were followed. Petri dishes with TY medium diluted 1:10 in distilled water, with $0.3 \%$ and $0.5 \%$ Britania agar, for swimming and swarming respectively, were used. For the swimming test, the plates were inoculated with a sterile pointed wire from a bacterial culture colony grown on plates with LB (1.5\% agar). For the swarming assay, plates were inoculated with $3 \mu \mathrm{l}$ of a liquid culture in LB medium in stationary phase. Both were incubated at $30^{\circ} \mathrm{C}$ for $72 \mathrm{~h}$. The images were taken with a Syngene G: BOX image analyser.

To determine twitching motility, the methodology described by Haley et al. (2014) was followed. Bacteria colonies grown in Petri dishes with LB medium (1.5\% agar) for $24 \mathrm{~h}$ at $28{ }^{\circ} \mathrm{C}$, were transferred by means of a puncture with a sterile pointed tip on plates containing LB or TY medium (1\% agar). The plates were incubated at $37{ }^{\circ} \mathrm{C}$ for $48 \mathrm{~h}$, then at room temperature for an additional $48 \mathrm{~h}$. The agar was removed from the plate and the twitching area was visualized by staining with $1 \%$ crystal violet.

\subsection{Electron microscopy}

Microscopic observations was performed through a confocal microscopy service with a Leica TCS SP5 Confocal Laser Microscope (CLSM) equipped with 7 laser lines, AOTF (Acousto-Optic Tunable Filter), AOBS (Acousto-Optical Beam Splitter) and scanning system (Tandem-scanning system SP5) for High resolution work suitable for in vivo material (School of Exact Sciences, Universidad Nacional de La Plata). 


\subsection{Root exudates collection}

Peanut (Arachis hypogaea L. cultivar Granoleico), maize (Zea mays SYN860 TD/TG from Syngenta) and soybean (Glycine max NS4611 STS from Nidera) seeds were disinfected following the method of Vincent (1970). They were immersed in $96^{\circ}$ ethanol for $30 \mathrm{~s}$, the alcohol was discarded and hydrogen peroxide $\left(\mathrm{H}_{2} \mathrm{O}_{2}\right) 15 \%$ was added for $15 \mathrm{~min}$. Finally, six washes were performed with sterile distilled water. Disinfected seeds were deposited in sterile Petri dishes containing moist cotton and paper filter and incubated at $28{ }^{\circ} \mathrm{C}$ in darkness until radicle reached a length of $2-3 \mathrm{~cm}$. The pregerminated seeds were transferred to Jensen tubes containing $15 \mathrm{ml}$ of Hoagland liquid medium (diluted 1:4 with water) (Hoagland and Arnon, 1950) and after 7 days of incubation in a growth chamber ( $16 \mathrm{~h}$ day $/ 8 \mathrm{~h}$ night cycle, at a constant temperature of $28^{\circ} \mathrm{C}$ ), the liquid medium containing the root exudates (RE) was collected. RE were concentrated by lyophilisation and suspended in sterile Milli-Q water in a volume necessary to achieve a $20 \mathrm{X}$ concentration of each plant. RE were sterilized by filtration with a cellulose acetate membrane of $0.22 \mu \mathrm{m}$ in pore diameter and conserved at $-20^{\circ} \mathrm{C}$.

\subsection{Chemotaxis assays}

The chemotaxis assay was performed through a capillary following the technique described by Mazumder et al. (1999). One hundred $\mu \mathrm{l}$ of a bacterial culture with an approximate concentration of $3 \times 10^{8} \mathrm{CFU}$ $\mathrm{ml}^{-1}$ was placed in a $200 \mu \mathrm{l}$ disposable pipette tip used as chamber. A 1 $\mathrm{ml}$ BD Plastipak syringe was used, with 25G 5/8 needle as a chemotaxis capillary containing $100 \mu \mathrm{l}$ of the different RE (10X). As controls, a syringe with $100 \mu \mathrm{l}$ of Milli-Q water and another containing 10X Hoagland medium were used.

The "needle + syringe" capillary was inserted into the pipette tip containing the bacterial cell suspension. After $45 \mathrm{~min}$ of incubation at room temperature, the "needle + syringe" was removed from the bacterial suspension and the content was diluted in physiological solution. The dilutions were seeded through the micro drop technique on Petri dishes with solid LB medium. The accumulation of bacteria in the capillaries was calculated as $\mathrm{CFU}$. $\mathrm{ml}^{-1}$ obtained according to the microdrop technique described above.

\subsection{Biofilm bacterial production in different culture media and in the presence of root exudates}

The biofilm formation assay was performed following the methodology proposed by O'toole. and Kolter (1998). To evaluate the formation of biofilm in different culture media, LB and TY were used as rich media, NBRIP-Psol and NBRIP as minimal media.

Two hundred $\mu \mathrm{l}$ of a culture (OD620nm $=0.01$ ) obtained from a dilution of an overnight culture, with or without root exudates (final concentration $1 \mathrm{X}$ ), was added to each well of 96-well polystyrene microplates. The plates were incubated at $36^{\circ} \mathrm{C}$ for $48 \mathrm{~h}$ and then at 25 ${ }^{\circ} \mathrm{C}$ during additional $48 \mathrm{~h}$.

Planktonic cells were gently homogenized and bacterial growth was determined by measuring O.D. at $600 \mathrm{~nm}$. Wells were washed with 200 $\mu \mathrm{l}$ of PBS (phosphate buffered saline) and stained for 15 min with $200 \mu \mathrm{l}$ of $0.1 \%$ crystal violet solution (CV) in $5 \%$ ethanol. Each well was then rinsed with water. The retained dye in the adhered cells was resuspended with $200 \mu \mathrm{l}$ of ethanol: acetone (80:20) solution added to the wells and incubated at room temperature for $30 \mathrm{~min}$. The O.D. at $570 \mathrm{~nm}$ of resuspended CV was determined using an Epoch тм Microplate spectrophotometer. The amount of biofilm produced, based on the number of bacteria contained in each well, was estimated by determining the Biofilm formation Index (BI) from the following formula: $\boldsymbol{B I}$ $=O D_{570} / O D_{600}$

\subsection{Statistical analysis}

Data were analysed using the software INFOSTAT (Di Rienzo et al., 2018). Previous to analysis, data were controled to comply with the assumptions of normality and homocedasticity. Variables were analysed with multifactorial ANOVA considering as factors the (1) independent assays, (2) treatments with addition of RE. Comparison of means was conducted using the protected test of Fisher (i.e., LSD), with a significance level of 0.05 .

\section{Results}

\subsection{Motility of native endophytic phosphate solubilizing strains Serratia sp. S119 and Enterobacter sp. J49}

It was observed that both strains have swarming (Fig. 1A and B), swimming (Fig. 1C and D), and twitching (Fig. 2) motility. For the former, and based on the description of Kearns (2010), both bacteria presented a colony of swarming motility in the form of dendrites. Since swarming and swimming motility are associated with the action of flagella, a microscopic observation of both strains was performed. Electronic microscopy confirmed the presence of flagella in both bacterial strains (Fig. 1E and F). In relation to twitching that was analysed in two different media, this motility was greater in TY medium than in the LB medium for both strains (Fig. 2).
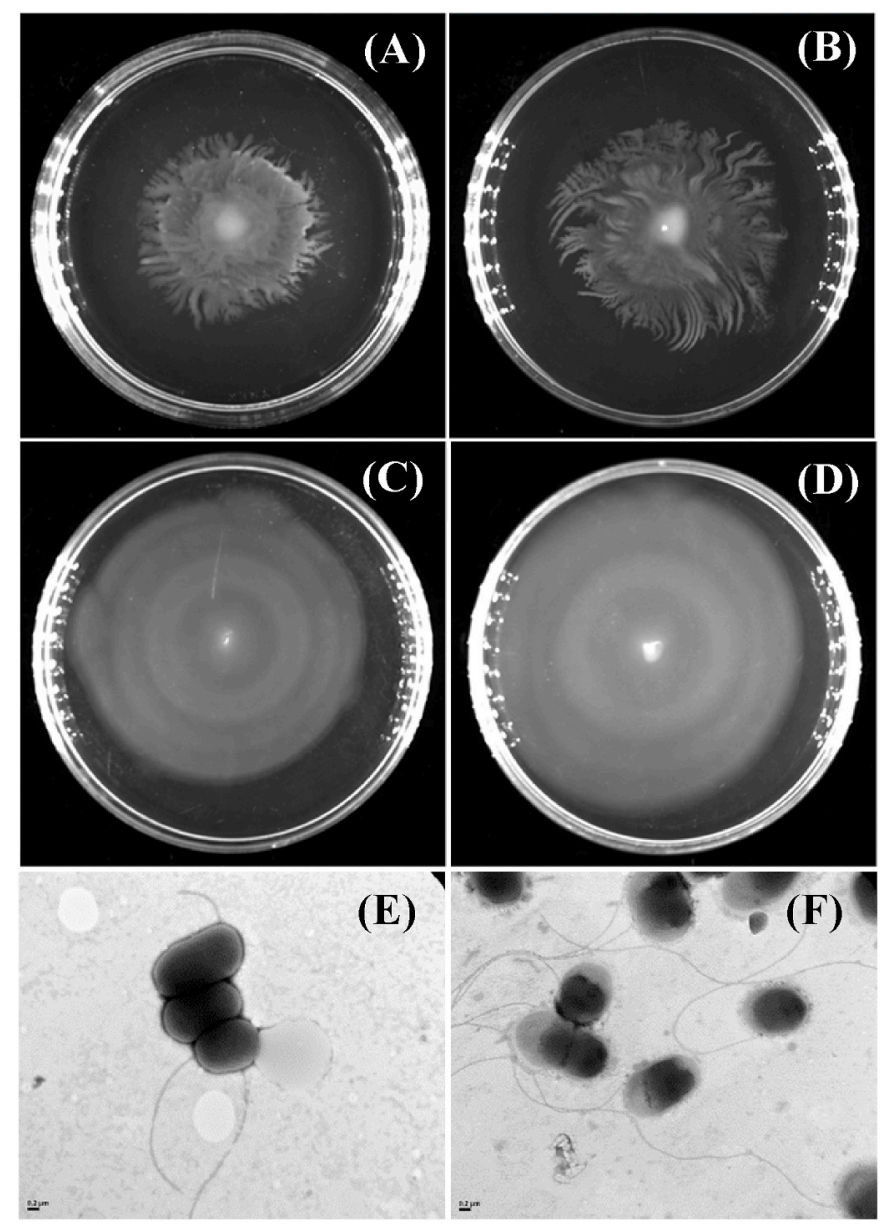

Fig. 1. Swarming (A and B) and swimming (C and D) motility on TY plates containing $0.5 \%$ and $0.3 \%$ agar respectively, after $72 \mathrm{~h}$ of incubation at $30{ }^{\circ} \mathrm{C}$ of Enterobacter sp. J49 (A and C), Serratia sp. S119 (B and D). Electron microscopy of flagellar structures of Enterobacter sp J49 (E) and Serratia sp. S119 (F). Magnification $\times 30000$. 

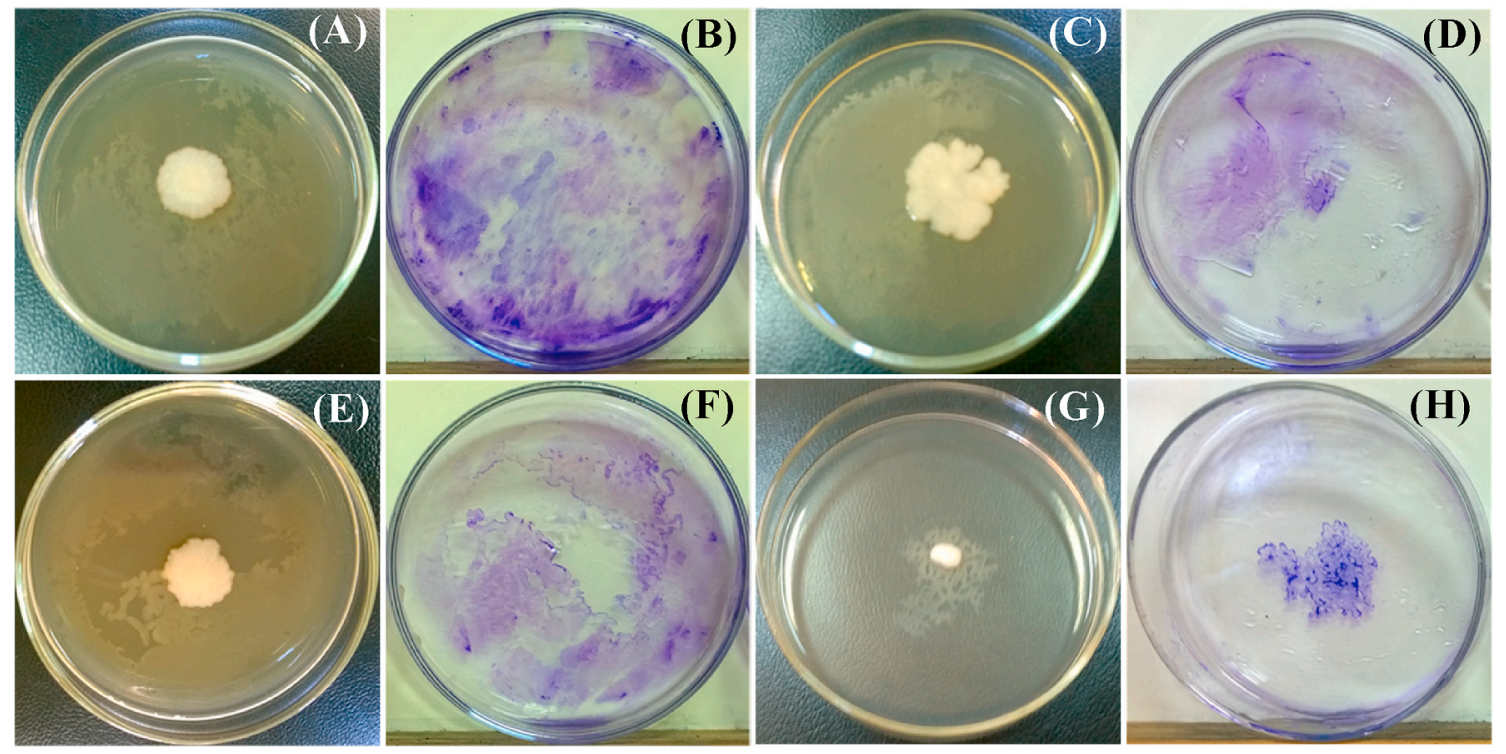

Fig. 2. Twitching motility on TY (A, B, E and F) and LB (C, D, G and H) plates containing 1\% agar of Enterobacter sp. J49 (A and C: Petri dish with agar, B and D: Petri dish without agar and stained with $1 \%$ crystal violet) and Serratia sp. S119 (E and F: Petri dish with agar, G and H: Petri dish without agar and stained with 1\% crystal violet). (For interpretation of the references to color in this figure legend, the reader is referred to the Web version of this article.)

\subsection{Chemoattractant effect of root exudates}

In order to select an incubation time in the experiments to study chemotactic motility, growth curves of both strains were performed and the maximum generation time $\left(\mathrm{GT}_{\max }\right)$ was determined. It was possible

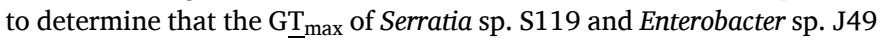
were 60 and $66 \mathrm{~min}$, respectively. Based on the GT values obtained from each bacterium, a capillary incubation time of $45 \mathrm{~min}$ was established for the chemotaxis test. It was possible to observe a chemoattractant effect of soybean and maize RE towards Serratia sp. S119 (Fig. 3A). In the case of Enterobacter sp. J49, peanut and soybean root exudates had an attractive effect on this bacterium (Fig. 3B).

\subsection{Production of biofilm by Serratia sp. S119 and Enterobacter sp. J49} in the presence of root exudates

In parallel to biofilm formation analysis, the phosphate solubilization of both strains was quantified in order to establish possible relationship between this capacity and the formation of biofilm in the different minimal culture media. The maximum amount of phosphate solubilized by the native isolate Serratia sp S119 was $0.936 \pm 0.114 \mathrm{~g}^{-1}$
$\mathrm{P}$ obtained at $48 \mathrm{~h}$ of growth (Table 1). This value was higher than that reached by strain Enterobacter sp. J49, which obtained a maximum solubilization value of $\mathrm{P}$ of $0.326 \pm 0.015 \mathrm{~g} \mathrm{l}^{-1} \mathrm{P}$ at $144 \mathrm{~h}$ of growth.

Initially, it was observed that in rich media Serratia sp. S119 presented a significantly higher Biofilm formation Index (BI) in TY than in LB at all tested times (Fig. 4A). Enterobacter sp. J49 showed no difference

Table 1

Average phosphorus concentrations solubilized by Enterobacter sp. J49 and Serratia sp S119 in NBRIP medium.

\begin{tabular}{lll}
\hline \multirow{2}{*}{ Time (hours) } & \multicolumn{2}{l}{ Solubilized phosphorus $(\mathrm{g} / \mathrm{l})$} \\
\cline { 2 - 3 } & Serratia sp. S119 & Enterobacter sp. J49 \\
\hline $\mathbf{2 4}$ & $0.383 \pm 0.056$ & $0.112 \pm 0.008$ \\
$\mathbf{4 8}$ & $0.936 \pm 0.114$ & $0.157 \pm 0.005$ \\
$\mathbf{7 2}$ & $0.876 \pm 0.073$ & $0.207 \pm 0.013$ \\
$\mathbf{9 6}$ & $0.873 \pm 0.050$ & $0.269 \pm 0.031$ \\
$\mathbf{1 2 0}$ & $0.922 \pm 0.087$ & $0.316 \pm 0.047$ \\
$\mathbf{1 4 4}$ & $0.816 \pm 0.121$ & $0.326 \pm 0.015$ \\
$\mathbf{1 6 8}$ & $0.883 \pm 0.136$ & $0.324 \pm 0.015$ \\
\hline
\end{tabular}

The data represent the mean \pm SE $(n=8)$.

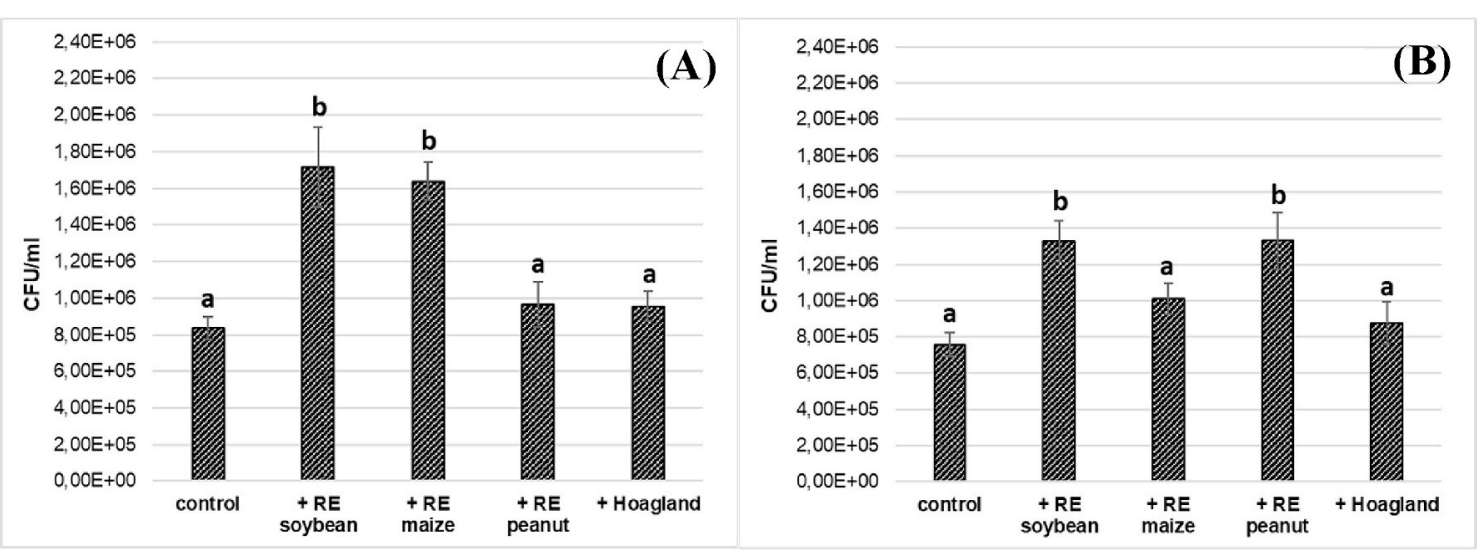

Fig. 3. Number of cells of strain (A) Serratia sp. S119, (B) Enterobacter sp. J49 expressed in CFU. $\mathrm{ml}^{-1}$ indicating chemotactic response to the different root exudate (RE) treatments of soybean, maize and peanuts. Control treatments: $\mathrm{H}_{2} \mathrm{O}$ Milli-Q and solution Hoagland. Each data is the average \pm 1 standard error (SE; $\mathrm{n}=18$ ). Different letters indicate significant differences $(\mathrm{p}>0.05)$ between treatments. 
in $\mathrm{BI}$ between rich media in most of the times analysed (Fig. 4B). In minimal media, it was possible to observe that Serratia sp S119 produced higher BI in NBRIP-Psol medium in contrast to NBRIP. On the contrary, Enterobacter sp. J49 strain showed a greater BI in this last medium.

Analysis of the effect of root exudates on biofilm formation indicated that Serratia sp. S119 showed variability over the time evaluated (Fig. 5A) on LB medium and against the different RE used. The addition of peanut RE in the four times evaluated produced the lowest BI values. In the case of the treatment without addition of RE, the BI increased during the days reaching a significantly higher value at $96 \mathrm{~h}$. It was also possible to observe that after $72 \mathrm{~h}$ the BI values in the presence of the three RE decreased in relation to control treatment. In TY medium, Serratia sp. S119 showed higher BI than in LB medium and the effect of RE was not significant (Fig. 5B). In most treatments, the maximum BI value was reached after $24 \mathrm{~h}$. As with LB medium, the addition of RE produced a decrease on the BI after $72 \mathrm{~h}$. In NBRIP minimal medium, Serratia sp. S119 showed a decrease of more than $50 \%$ in BI when it grew in the presence of each of the three $\mathrm{RE}$ in the four times evaluated (Fig. 5C). In the NBRIP-Psol medium, the highest BIs were detected for treatment without RE after $48 \mathrm{~h}$ (Figs. $4 \mathrm{~A}$ and 5D). The decrease in $\mathrm{BI}$ due to the addition of REs could be observed after $48 \mathrm{~h}$ (Fig. 5D).

Regarding Enterobacter sp. J49, the addition of RE in LB rich medium produced a significant decrease in BI at $48 \mathrm{~h}$, which was reversed at $72 \mathrm{~h}$, time in which the four treatments reached highest BI value (Fig. 5E). At $96 \mathrm{~h}$ a new decrease in BI was observed for treatments with maize and peanut RE. In the case of TY rich medium, the addition of peanut RE at all times evaluated showed no significant differences with respect to the control treatment (Fig. 5F). The RE of soybean and maize, significantly decreased the BI of the strain at $48 \mathrm{~h}$. On both minimal media, this parameter was significantly decreased with the addition of the three RE at all times tested (Fig. 5G and H).

\section{Discussion}

Rhizosphere colonization is an important trait when looking for microorganisms to be applied for beneficial purposes for plants. The ineffectiveness of PGPB in the field has often been attributed to their inability to colonize plant roots (Benizri et al., 2001; Bloemberg and Lugtenberg, 2001). In addition, PGPB generally improve plant growth by colonizing the root system and preventing the establishment or suppression of harmful microorganisms of the rhizosphere (Schroth and Hancock, 1982). For this, these bacteria must be able to compete with soil microorganisms and efficiently colonize the rhizosphere of plants. Bacterial motility is one of the features necessary for a successful colonization. In this study, it was determined that both strains analysed showed swimming, swarming and twitching motility. The motility capacity mediated by flagella coincides with previous studies for these bacterial genera (Mishra et al., 2016; Choi et al., 2015). Thus, structures related to swarming and swimming motility types have been reported in other studies to be present in bacteria of the Serratia and Enterobacter genera (Périamé et al., 2015; Alberti and Harshey, 1990; Eberl et al., 1999). In addition and considering that both strain are endophytes it is important to consider that flagellar motility (swimming and swarming) and contraction motility (twitching) has been described to play an important role in the colonization of the root (Harjai and Sabharwal, 2017).

Considering twitching motility, several studies determine that this bacterial capacity is possible to be shown through staining with Crystal Violet of bacterial growth that occurs at the interface between the agar medium and the Petri dish (Rotcheewaphan et al., 2016; Tomada et al., 2016). In addition, studies with mutants of Azoarcus spp., defective in the production of type IV pili, demonstrated the importance of this cell structure in twitching motility, not only to join the surface of the plant but also to colonize the inside of the root (Böhm et al., 2007). The mutants showed a strongly reduced ability to invade the roots compared to the wild type of bacteria. Considering that the strains of the present study were isolated from the inside of peanut root nodules, it is possible to suggest that their endophytic colonization capacity could be mediated by twitching motility. In the present work twitching motility was studied by using this strategy and it was analysed on different bacterial media. Through these assays, it was possible to observe that both bacteria showed greater twitching motility in TY medium with respect to the LB medium being more evident for Serratia sp. S119 strain that for the Enterobacter sp. J49 strain. The most noticeable difference between the media used is in the salt that is added. $\mathrm{LB}$ contains $\mathrm{NaCl}$ and $\mathrm{TY} \mathrm{CaCl}_{2}$ so the observed differences in twitching motility could be attributed to the difference between cation composition of the media. In particular, calcium $\left(\mathrm{Ca}^{2+}\right)$ has been described to modulate a variety of bacterial phenotypes, among which are motility (Parker et al., 2015; Guragain et al., 2013), support adherence (Mongiardini et al., 2008; Ausmees et al., 2001) and the synthesis of EPS (Patrauchan et al., 2007). In particular, in a study by Cruz et al. (2014), a specific regulatory function of $\mathrm{Ca}^{2+}$ in twitching motility was identified. In this study authors found that $\mathrm{Ca}^{2+}$ binds to a motif of the pili type IV protein and produced a greater contraction.

Chemotaxis of beneficial bacteria generated by root exudates is a necessary requirement for efficient root colonization (Allard-Massicotte et al., 2016; Scharf et al., 2016). Studies on attraction and migration of beneficial rhizosphere bacteria provide important information on ecological traits for root colonization. Chemical signalling between plant roots and other soil organisms, including the roots of neighboring plants, is often based on chemical substances derived from the roots. A variety of compounds present in root exudates, attract a wide range of microbial populations to survive on and within their tissues, including the aerial parts, the vascular network and the radical tissues located beneath the soil (Khan et al., 2017). Plant exudates are released at specific sites, and many bacteria prefer to mobilize and colonize different positions on the plant surface with optimal nutrient availability
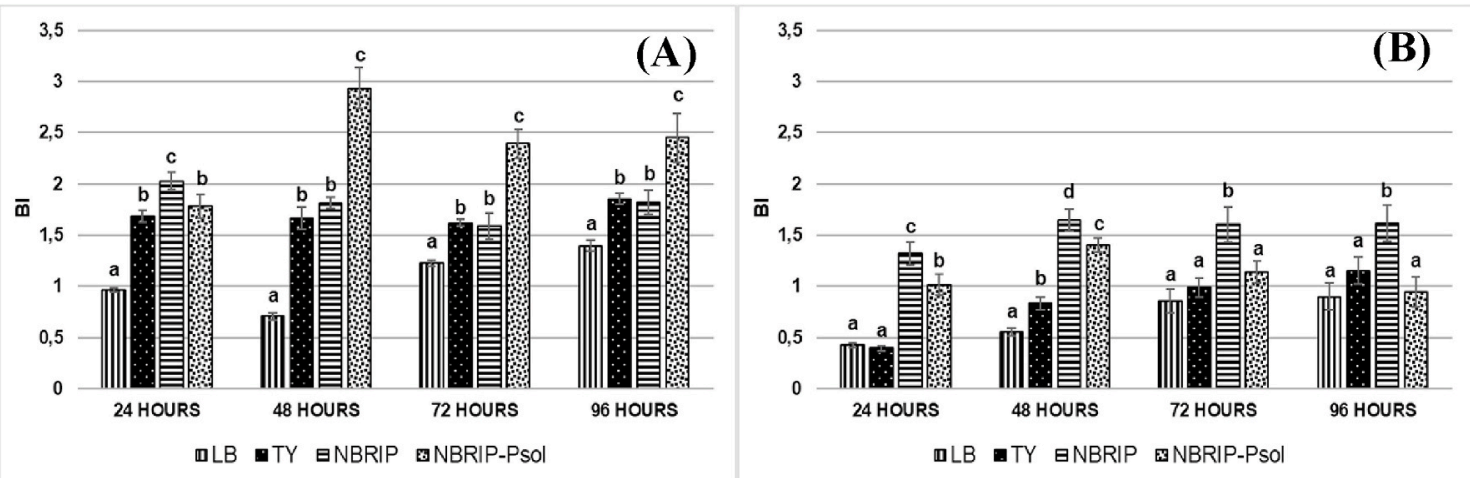

Fig. 4. Effect of the culture medium on biofilm formation index (BI) of strain (A) Serratia sp. S119 and (B) Enterobacter sp. J49. 

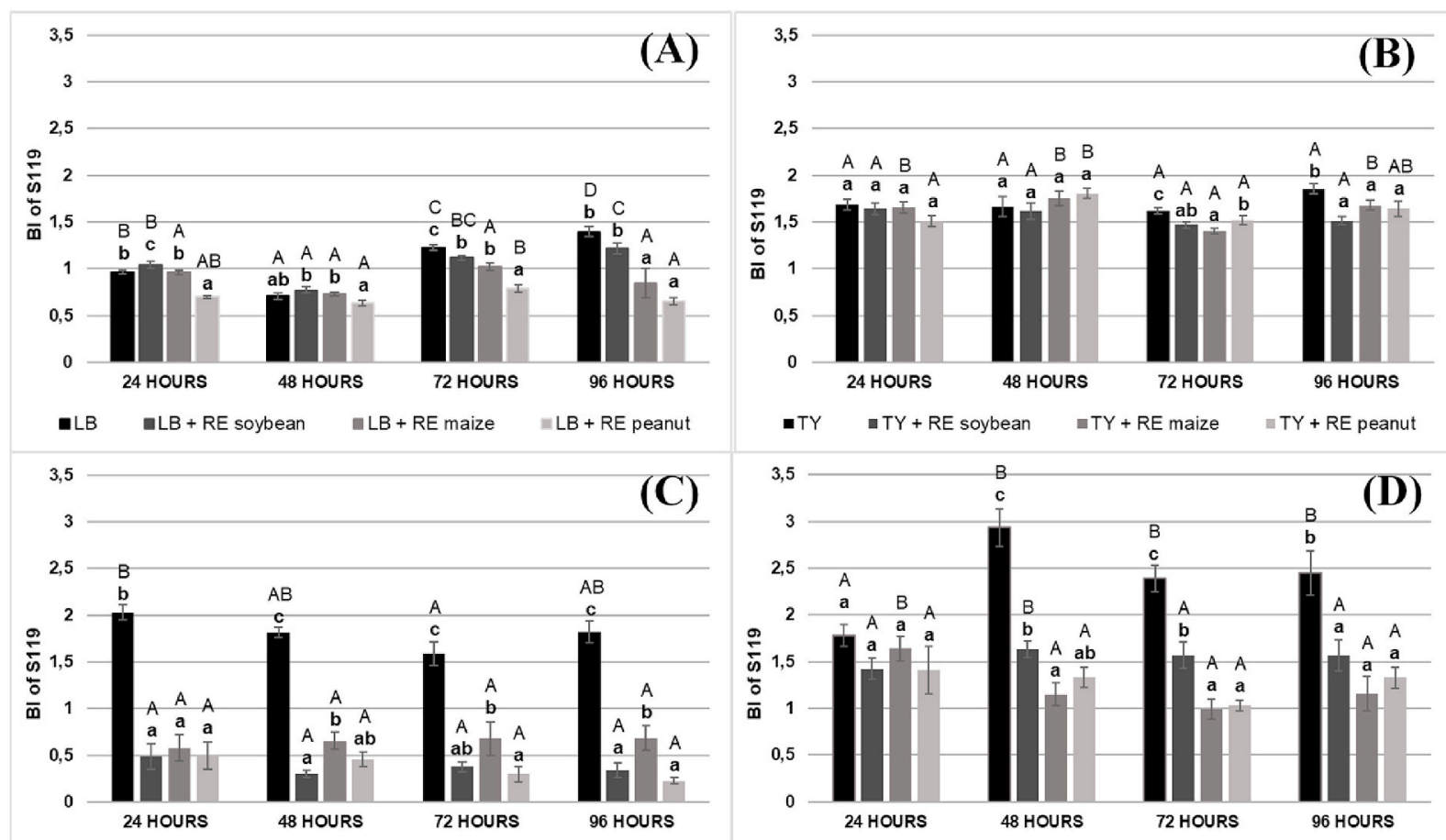

-NBRIP $\quad$ NBRIP + RE soybean $\backsim N B R I P+R E$ maize $\quad$ NBRIP + RE peanut

- NBRIP-Psol n NBRIP-Psol + RE soybean " NBRIP-Psol + RE maize - NBRIP-Psol + RE peanut

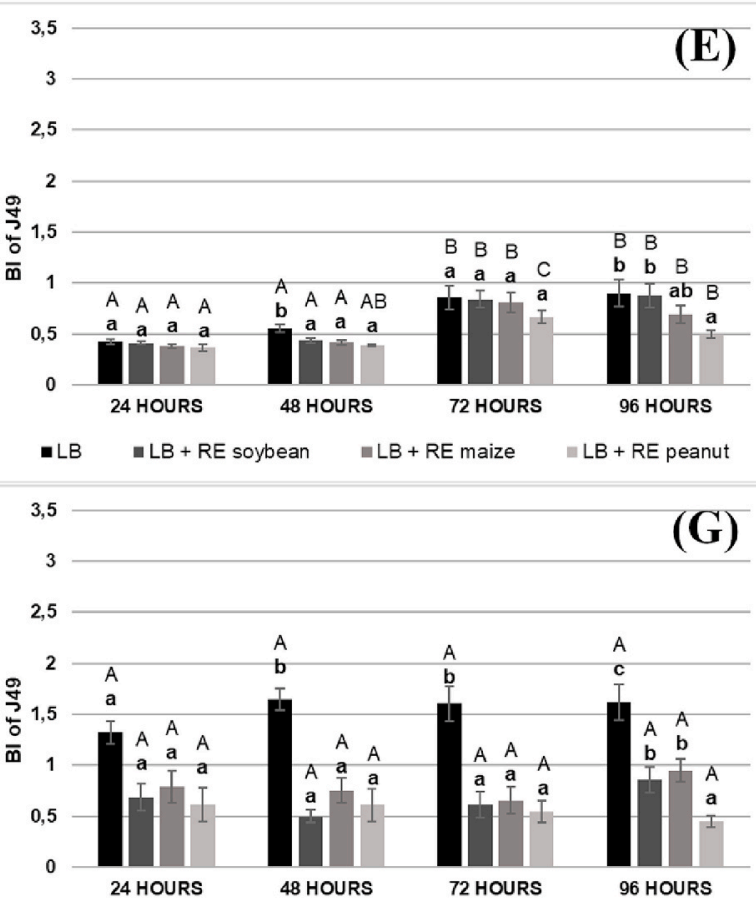

-NBRIP $=N B R I P+R E$ soybean $₫ N B R I P+R E$ maize $₫ N B R I P+R E$ peanut

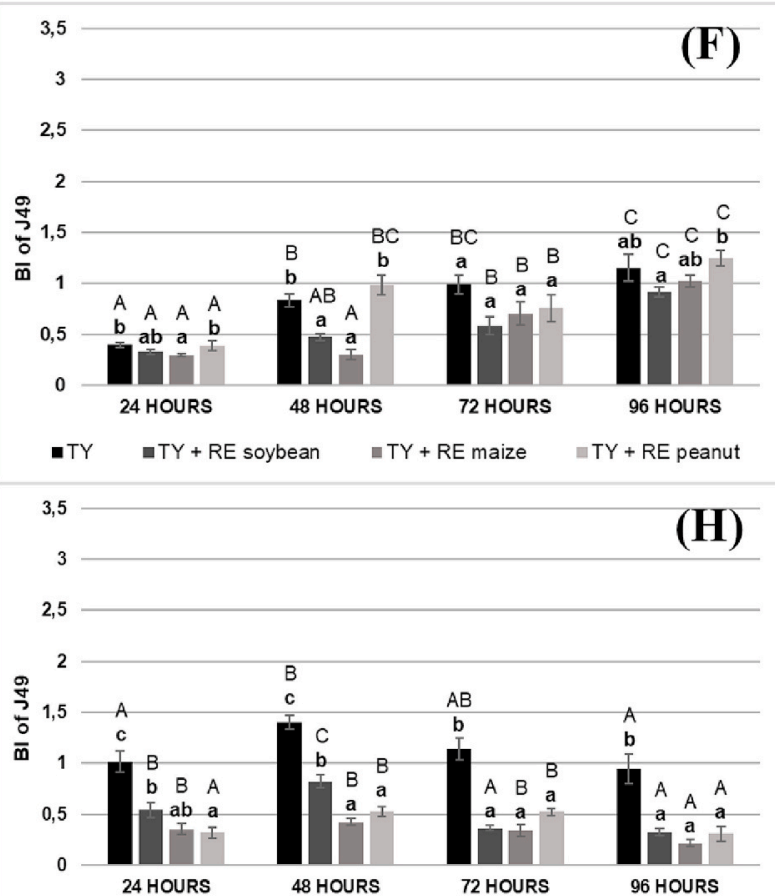

-NBRIP-Psol $₫$ NBRIP-Psol + RE soybean $₫$ NBRIP-Psol + RE maize $₫$ NBRIP-Psol + RE peanut

Fig. 5. Biofilm index of Serratia sp. S119 (A-D) and Enterobacter sp. J49 (E-H) growing in the presence of root exudates (RE) of soybean, maize and peanut plants on the biofilm formation index (BI) in (A and E) LB, (B and F) TY, (C and G) NBRIP and (D and H) NBRIP-Psol media. The data represent the mean \pm SE ( $=16$ ). Different letters above in uppercase indicate significant differences $(p<0.05)$ between times for the same treatment. Different lowercase letters below indicate significant differences $(\mathrm{p}<0.05)$ between treatments for the same time.

(Danhorn and Fuqua, 2007). Han and Cooney (1993) found that an isolation of Serratia sp. Gil-1 showed positive chemotaxis against different concentrations of aspartate. On the other hand, Enterobacter aerogenes presented a good chemotaxis for maltose and aspartate while a strain of Serratia marcescens showed no significant responses to maltose or aspartate, while it was attracted to casaminoacids (Dahl and Manson, 1985). As mentioned earlier, the results obtained from this study indicate that endophytic peanut bacteria were differentially attracted to the RE of the plants to which they were exposed. Enterobacter sp. J49 strain showed a positive attraction towards RE of peanut, its host plant, to the same extent as with those of soybean, which also belongs to the legume group, while it was not chemoattracted towards RE of maize. There are reports by other authors that bacterial isolates are more attracted to the RE of their host plant, than those secreted by a non-host 
plants (Yao and Allen, 2006; Mandimba et al., 1986). On the other hand, the strain Serratia sp. S119 was not attracted to peanut's RE, its host plant, while it did so against the RE of soybean and maize plants. Yaryura et al. (2008) found that B. amyloliquefaciens and B. japonicum did not show chemotaxis induced by the exudates of their macrosymbiont soybean. Nevertheless, Bacilio-Jiménez et al. (2003), suggested that the chemoattractant characteristics of the RE would favour the endophytic microorganisms and could induce the exclusion of other colonizing microorganisms from the ecological niche. These results demonstrate the differential attraction of soil bacteria to molecules secreted by plants and would explain the different chemotaxis observed by the strains.

The formation of bacterial biofilms is of importance for agriculture. Bacterial biofilms established in plant roots could protect colonization sites and reduce the availability of root exudates and nutritional elements to decrease pathogen development and subsequent root colonization (Weller and Thomashow, 1994). The analysis of biofilm formation produced by the strains was performed on four different culture media in order to determine the effect that different growth conditions have on the biofilm formation index (BI). For this rich and minimal media were selected for comparing. In the case of rich media, LB and TY were chosen given that there were differential results in twitching motility of the both strains studied when growing on them. In addition to this, it is documented that the formation of biofilm is influenced by the presence of type IV pili that characterizes this motility (Koczan et al., 2009). It is possible to correlate the results obtained for the formation of biofilms in rich medium, with those obtained for the analysis of twitching, given that in medium TY presented greater motility and greater BI was seen. Relationship between the formation of biofilms and twitching motility is consistent with studies of other authors who found that the retractable movement of type IV pili, acts as cross-linking structures, allowing the bacteria to spread over the surface and form biofilms (Fong and Yildiz, 2015). In addition, it has been observed that mutants with poor synthesis of these type IV pili proteins cannot form biofilms (Khan et al., 2017; Elhenawy et al., 2015). Furthermore, $\mathrm{Ca}^{2+}$ supplementation, as occurs in the TY medium, has been shown to promote the formation of biofilms in different bacterial genera (Das et al., 2014; Cruz et al., 2012; Rinaudi et al., 2006), among them Enterobacter cloacae (Zhou et al., 2014). Cruz et al. (2012), observed an increase in the formation of biofilms when the medium was supplemented with at least $1 \mathrm{mM} \mathrm{Ca}^{2+}$. Considering this, the observed difference regarding the formation of biofilms in the two rich culture media used, could be attributed to the $\mathrm{Ca}^{+2}$ contribution of the TY medium, in which a concentration of $5.94 \mathrm{mM} \mathrm{Ca}^{2+}$ is incorporated through of one of its components, $\mathrm{CaCl}_{2}$, a value that is above the reported concentrations.

On the other hand, the NBRIP minimal medium (Mehta and Nautiyal, 2001) was selected because it is a selective medium for phosphate solubilizing bacteria, PGPB property of the strains under study, and compared with the same medium replacing the insoluble phosphate source $\left(\mathrm{Ca}_{3}\left(\mathrm{PO}_{4}\right)_{2}\right)$, for $\mathrm{KH}_{2} \mathrm{PO}_{4}$, which is a soluble source of $\mathrm{P}$ (NBRIP-Psol). Phosphate solubilizing capacity of the strains under study has been previously described (Ludueña et al., 2017; Taurian et al., 2010). However, in this work it was quantified again in parallel to Biofilm formation Index (BI) estimation in order to establish possible relationship between this capacity and the formation of biofilms in the different culture media. It was possible to observe that both strains showed the same pattern of phosphate solubilization curves than those previously reported but reaching higher values of solubilized $\mathrm{P}$ because higher stirring conditions was used in this study. The comparison between the amount of $\mathrm{P}$ solubilized by the bacteria, with that incorporated as soluble $P$ in the NBRIP-Psol medium, allows us to infer in which of the two conditions it generates greater stress due to deficiency of P. As described, the strain Serratia sp. S119 showed maximum solubilization at $48 \mathrm{~h}$ of growth reaching values of soluble $\mathrm{P}$ in the NBRIP medium that exceed the concentration of this nutrient added in the NBRIP-Psol medium (3 g. $1^{-1}$ of $\mathrm{KH}_{2} \mathrm{PO}_{4}$, which is equivalent to a $\mathrm{P}$ concentration of
$0.68 \mathrm{~g} \mathrm{l}^{-1}$ ). Only at $24 \mathrm{~h}$, a lower P content than the NBRIP-Psol medium was detected and would explain the greater BI at this grow time. In the case of Enterobacter sp. J49, which reached its maximum phosphate solubilization at $144 \mathrm{~h}$ of growth $\left(0.326 \mathrm{~g} \mathrm{l}^{-1}\right.$ of P), its solubilization capacity would give it a lower concentration of $P$ in the four tested times than that added in the NBRIP-Psol medium. The impact of low P availability on biofilms depends on the organism and its role in the ecosystem. P limitation has been reported to increase the density of the biofilm of A. tumefaciens (Danhorn et al., 2004) and R. leguminosarum bv. trifolii (Janczarek and Skorupska, 2011). Considering that a lower availability of $\mathrm{P}$ would generate a stress condition, and to induce the formation of biofilms as a form of survival, it is feasible to infer that the results obtained could be explained from the point of view of the availability of this nutrient in the culture media used.

Recent studies on the root-microorganism interaction have shown that bacteria can colonize the root and at the same time form biofilms. This phenomenon is considered a survival strategy by rhizobacteria which provide protection for themselves and the plant against stress conditions (Timmusk and Nevo, 2011). Motility is involved not only in the beginning and development of biofilms, but also in their dispersion being an essential mechanism for the propagation and colonization of new habitats (Sauer et al., 2002) such as the rhizosphere. For this purpose, another property analysed in the bacteria was its ability to produce biofilm and the effect that root exudates have on this property. In the epiphytic or endophytic colonization process, several steps occur such as the attraction of microbes to the root, adhesion, colonization and growth (Nihorimbere et al., 2010). While, at a distance from the root, exudates improve transcription levels of the chemoreceptor genes promoting chemotaxis, this process is reversed in the vicinity of the root, where the need for chemotaxis towards the root may be less important (López-Farfán et al., 2019). Accordingly, Corral-Lugo et al. (2016) established a link between the absence of chemotaxis and the formation of biofilms, since the mutation of specific chemoreceptor genes resulted in a greater formation of biofilm. Numerous studies have investigated the impact of root exudates on transcription levels of chemotaxis and motility genes, and showed that almost all chemoreceptor transcripts decreased at a high concentration of RE (Webb et al., 2016; Oku et al., 2012). In this regard, in the present study chemotaxis of the bacteria towards RE was analysed employing a concentration of $10 \mathrm{X}$ and a chemoattractant effect was observed. On the other hand, biofilm production was analysed using a $1 \mathrm{X}$ RE concentration and a decrease of BI was observed. Thus, this could suggest that at the $1 \mathrm{X}$ RE concentration used in this work, the biofilm formation genes of the bacteria were probably not induced, with those of chemotaxis prevailing. It is possible to speculate that probably genes related to chemotaxis are activated on both $1 \mathrm{X}$ and 10X RE concentrations and a greater concentration higher than $10 \mathrm{X}$ is required to observe an increase in BI. Another aspect to consider is that eukaryotic organisms, including plants, produce different molecules capable of interfering with bacterial quorum sensing systems (Gao et al., 2003). Therefore, it is possible to speculate that in the RE of the plants under study there were molecules that interfere with the quorum sensing communication of the bacteria, reducing their ability to form biofilms.

The results of the present study, although preliminary, allow to suggest that non-symbiotic endophytic bacteria present more than one type of motility and that chemotaxis toward RE is variable as hypothesized. In addition, biofilm production of bacteria are also influenced by $\mathrm{RE}$ concentration and the composition suggesting a nutrient dependent phenotype as mentioned. Further studies are necessary to confirm what it is speculated and to gain more knowledge on what happens in the soil environment. Other factors could be influencing motility and chemical signalling processes such as the other microorganisms inhabiting the same ecosystem both in a negative or positive manner. 


\section{Conclusion}

The motility and biofilm formation properties of the native peanut phosphate solubilizing strains Serratia sp. S119 and Enterobacter sp. J49 could be involved in their capacity of endophytic colonization. The changes produced by the addition of root exudates in the production of chemotaxis and biofilms of the strains suggest that compounds released by the plants are detected by these bacteria and could be part of the molecular dialogue involved in their interaction with the roots of plant.

\section{Declaration of competing interest}

The authors declare that they have no known competing financial interests or personal relationships that could have appeared to influence the work reported in this paper.

\section{Acknowledgements}

This research was supported by Facultad de Ciencias Exactas y Naturales de la Universidad Nacional de La Pampa (FCEyN-UNLPam), Secretaría de Ciencia y Técnica de la Universidad Nacional de Río Cuarto (SECYT-UNRC), and Consejo Nacional de Investigaciones Científicas y Técnicas (CONICET), Agencia Nacional de Promoción Científica y Tecnológica (ANPCyT).

\section{References}

Alberti, L., Harshey, R.M., 1990. Differentiation of Serratia marcescens 274 in to swimmer and swarmer cells. J. Bacteriol. 172 (8), 4322-4328.

Allard-Massicotte, R., Tessier, L., Lécuyer, F., Lakshmanan, V., Lucier, J., Garneau, D., Caudwell, L., Vlamakis, H., Bais, H.P., Beauregard, P.B., 2016. Bacillus subtilis early colonization of Arabidopsis thaliana roots involve multiple chemotaxis receptors. mBio 7 (6) e01664-16.

Anzuay, M.S., Ciancio, M.G.R., Ludueña, L.M., Angelini, J.G., Barros, G., Pastor, N., Taurian, T., 2017. Growth promotion of peanut (Arachis hypogaea L.) and maize (Zea mays L.) plants by single and mixed cultures of efficient phosphate solubilizing bacteria that are tolerant to abiotic stress and pesticides. Microbiol. Res. 199, 98-109.

Anzuay, M.S., Frola, O., Angelini, J.G., Ludueña, L.M., Fabra, A., Taurian, T., 2013. Genetic diversity of phosphate-solubilizing peanut (Arachis hypogaea L.) associated bacteria and mechanisms involved in this ability. Symbiosis 60 (3), 143-154.

Ausmees, N., Jacobsson, K., Lindberg, M., 2001. A unipolarly located, cell-surfaceassociated agglutinin, RapA, belongs to a family of Rhizobium-adhering proteins (Rap) in Rhizobium leguminosarum bv. trifolii. Microbiology 147 (3), 549-559.

Bacilio-Jiménez, M., Aguilar-Flores, S., Ventura-Zapata, E., Pérez-Campos, E., Bouquelet, S., Zenteno, E., 2003. Chemical characterization of root exudates from rice (Oryza sativa) and their effects on the chemotactic response of endophytic bacteria. Plant Soil 249 (2), 271-277.

Bashan, Y., Holguin, G., 1998. Proposal for the division of plant growth-promoting rhizobacteria into two classifications: biocontrol-PGPB (plant growth-promoting bacteria) and PGPB. Soil Biol. Biochem. 30 (8), 1225-1228.

Behera, S., Arora, R., Nandhagopal, N., Kumar, S., 2014. Importance of chemical pretreatment for bioconversion of lignocellulosic biomass. Renew. Sustain. Energy Rev. 36, 91-106.

Benizri, E., Baudoin, E., Guckert, A., 2001. Root colonization by inoculated plant growthpromoting rhizobacteria. Biocontrol Sci. Technol. 11 (5), 557-574.

Beringer, J.E., 1974. R factor transfer in rhizobiurn zegurninosarum. J. Gen. Microbiol. 84, 188-198.

Bloemberg, G.V., Lugtenberg, B.J., 2001. Molecular basis of plant growth promotion and biocontrol by rhizobacteria. Curr Op Plant Biology 4 (4), 343-350.

Böhm, M., Hurek, T., Reinhold-Hurek, B., 2007. Twitching motility is essential for endophytic rice colonization by the N2-fixing endophyte Azoarcus sp. strain BH72. MPMI (Mol. Plant-Microbe Interact.) 20 (5), 526-533.

Choi, Y., Kim, S., Hwang, H., Kim, K.P., Kang, D.H., Ryu, S., 2015. Plasmid-encoded MCP is involved in virulence, motility, and biofilm formation of Cronobacter sakazakii ATCC 29544. Infect. Immun. 83 (1), 197-204.

Compant, S., Clément, C., Sessitsch, A., 2010. Plant growth-promoting bacteria in the rhizo-and endosphere of plants: their role, colonization, mechanisms involved and prospects for utilization. Soil Biol. Biochem. 42 (5), 669-678.

Corral-Lugo, A., De la Torre, J., Matilla, M.A., Fernández, M., Morel, B., EspinosaUrgel, M., Krell, T., 2016. Assessment of the contribution of chemoreceptor-based signalling to biofilm formation. Environ. Microbiol. 18 (10), 3355-3372.

Costerton, J.W., Cheng, K.J., Geesey, G.G., Ladd, T.I., Nickel, J.C., Dasgupta, M., Marrie, T.J., 1987. Bacterial biofilms in nature and disease. Annu. Rev. Microbiol. 41 (1), 435-464.

Costerton, J.W., Stewart, P.S., Greenberg, E.P., 1999. Bacterial biofilms: a common cause of persistent infections. Science 284 (5418), 1318-1322.
Cruz, L.F., Cobine, P.A., De La Fuente, L., 2012. Calcium increases Xylella fastidiosa surface attachment, biofilm formation, and twitching motility. Appl. Environ. Microbiol. 78 (5), 1321-1331.

Cruz, L.F., Parker, J.K., Cobine, P.A., De La Fuente, L., 2014. Calcium-enhanced twitching motility in Xylella fastidiosa is linked to a single PilY1 homolog. Appl. Environ. Microbiol. 80 (23), 7176-7185.

Dahl, M.K., Manson, M.D., 1985. Interspecific reconstitution of maltose transport and chemotaxis in Escherichia coli with maltose-binding protein from various enteric bacteria. J. Bacteriol. 164 (3), 1057-1063.

Danhorn, T., Hentzer, M., Givskov, M., Parsek, M.R., Fuqua, C., 2004. Phosphorus limitation enhances biofilm formation of the plant pathogen Agrobacterium tumefaciens through the PhoR-PhoB regulatory system. J. Bacteriol. 186 (14), 4492-4501.

Danhorn, T., Fuqua, C., 2007. Biofilm formation by plant-associated bacteria. Annu. Rev. Microbiol. 61, 401-422.

Das, T., Sehar, S., Koop, L., Wong, Y.K., Ahmed, S., Siddiqui, K.S., Manefield, M., 2014. Influence of calcium in extracellular DNA mediated bacterial aggregation and biofilm formation. Plos One 9 (3).

Di Rienzo, J.A., Casanoves, F., Balzarini, M.G., Gonzalez, L., Tablada, M., Robledo, C.W., 2018. InfoStat Versión 2018. Grupo InfoStat, FCA. Universidad Nacional de Córdoba, Argentina. URL. http://www.infostat.com.ar.

Eberl, L., Molin, S., Givskov, M., 1999. Surface motility of Serratia liquefaciens MG1. J. Bacteriol. 181 (6), 1703-1712.

Elhenawy, W., Scott, N.E., Tondo, M.L., Orellano, E.G., Foster, L.J., Feldman, M.F., 2015. Protein O-linked glycosylation in the plant pathogen Ralstonia solanacearum. Glycobiology 26 (3), 301-311.

Fiske, E.H., Subbarow, Y., 1925. The solubilization of phosphate: the action of various organic compounds on dicalcium and tricalcium phosphate. N. Z. J. Sci. Technol. 33, 436-444.

Fong, J.N., Yildiz, F.H., 2015. Biofilm matrix proteins. Microbiol. Spectr. 3 (2).

Gao, M., Teplitski, M., Robinson, J.B., Bauer, W.D., 2003. Production of substances by Medicago truncatula that affect bacterial quorum sensing. MPMI (Mol. Plant-Microbe Interact.) 16 (9), 827-834.

Glick, B.R., 2012. Plant Growth-Promoting Bacteria: Mechanisms and Applications. Scientifica, 2012.

Guragain, M., Lenaburg, D.L., Moore, F.S., Reutlinger, I., Patrauchan, M.A., 2013. Calcium homeostasis in Pseudomonas aeruginosa requires multiple transporters and modulates swarming motility. Cell Calcium 54 (5), 350-361.

Haley, C.L., Kruczek, C., Qaisar, U., Colmer-Hamood, J.A., Hamood, A.N., 2014. Mucin inhibits Pseudomonas aeruginosa biofilm formation by significantly enhancing twitching motility. Can. J. Microbiol. 60 (3), 155-166.

Han, G., Cooney, J.J., 1993. A modified capillary assay for chemotaxis. J. Ind. Microbiol. 12 (6), 396-398.

Hardoim, P.R., Van Overbeek, L.S., van Elsas, J.D., 2008. Properties of bacterial endophytes and their proposed role in plant growth. Trends Microbiol. 16 (10), 463-471.

Harjai, K., Sabharwal, N., 2017. Biofilm formation and quorum sensing in rhizosphere. Biofilms Plant Soil Health 111.

Harshey, R.M., 2003. Bacterial motility on a surface: many ways to a common goal. Annu. Rev. Microbiol. 57 (1), 249-273.

Hayat, S., Faraz, A., Faizan, M., 2017. Root exudates: composition and impact on plant-microbe interaction. Biofilms Plant Soil Health 179-193.

Hoagland, D.R., Arnon, D.I., 1950. The water-culture method for growing plants without soil. Circular California Agricultural Experiment Station 347 (2nd edit).

Janczarek, M., Skorupska, A., 2011. Modulation of rosR expression and exopolysaccharide production in Rhizobium leguminosarum bv. trifolii by phosphate and clover root exudates. Int. J. Mol. Sci. 12 (6), 4132-4155.

Jarrell, K.F., McBride, M.J., 2008. The surprisingly diverse ways that prokaryotes move. Nat. Rev. Microbiol. 6 (6), 466-476.

Kearns, D.B., 2010. A field guide to bacterial swarming motility. Nat. Rev. Microbiol. 8 (9), 634-644.

Khan, M.S., Altaf, M.M., Ahmad, I., 2017. Chemical Nature of Biofilm Matrix and its Significance. Biofilms in Plant and Soil Health, p. 151.

Koczan, J.M., McGrath, M.J., Zhao, Y., Sundin, G.W., 2009. Contribution of Erwinia amylovora exopolysaccharides amylovoran and levan to biofilm formation: implications in pathogenicity. Phytopathology 99 (11), 1237-1244.

López-Farfán, D., Reyes-Darias, J.A., Matilla, M.A., Krell, T., 2019. Concentration dependent effect of plant root exudates on the chemosensory systems of Pseudomonas putida KT2440. Front. Microbiol. 10 (78), 1-15.

Ludueña, L.M., Anzuay, M.S., Angelini, J.G., Barros, G., Luna, M.F., Monge, P., Fabra, A., Taurian, T., 2017. Role of bacterial pyrroloquinoline quinone in phosphate solubilizing ability and in plant growth promotion on strain Serratia sp. S119. Symbiosis 72 (1), 31-43.

Lugtenberg, B., Kamilova, F., 2009. Plant-growth-promoting rhizobacteria. Annu. Rev. Microbiol. 63, 541-556.

Lux, R., Shi, W., 2004. Chemotaxis-guided movements in bacteria. Crit. Rev. Oral Biol. Med. 15 (4), 207-220.

Mandimba, G., Heulin, T., Bally, R., Guckert, A., Balandreau, J., 1986. Chemotaxis of free-living nitrogen-fixing bacteria towards maize mucilage. Plant Soil 90 (1-3), $129-139$.

Mazumder, R., Phelps, T.J., Krieg, N.R., Benoit, R.E., 1999. Determining chemotactic responses by two subsurface microaerophiles using a simplified capillary assay method. J. Microbiol. Methods 37 (3), 255-263.

Mehta, S., Nautiyal, C.S., 2001. An efficient method for qualitative screening of phosphatesolubilizing bacteria. Curr. Microbiol. 43 (1), 51-56. 
Miller, J.H., 1972. Experiments in Molecular Genetics. Cold Spring Laboratory Press. Cold Spring Harbor, New York.

Mishra, A., Maltais, T.R., Walter, T.M., Wei, A., Williams, S.J., Wereley, S.T., 2016. Trapping and viability of swimming bacteria in an optoelectric trap. Lab Chip 16 (6), 1039-1046.

Molina, M.A., Ramos, J.L., Espinosa-Urgel, M., 2003. Plant-associated biofilms. Rev. Environ. Sci. Biotechnol. 2 (2), 99-108.

Mongiardini, E.J., Ausmees, N., Pérez-Giménez, J., Althabegoiti, J.M., Quelas, I.J., López-García, S.L., Lodeiro, A.R., 2008. The rhizobial adhesion protein RapA1 is involved in adsorption of rhizobia to plant roots but not in nodulation. FEMS Microbiol. Ecol. 65 (2), 279-288.

Nievas, F., Bogino, P., Sorroche, F., Giordano, W., 2012. Detection, characterization, and biological effect of quorum-sensing signaling molecules in peanut-nodulating bradyrhizobia. Sensors 12 (3), 2851-2873.

Nihorimbere, V., Ongena, M., Brostaux, Y., Kakana, P., Jourdan, E., Thonart, P., 2010. Beneficial effects of Bacillus subtilis on field-grown tomato in Burundi: reduction of local Fusarium disease and growth promotion. Afr. J. Microbiol. Res. 4 (11), 1135-1142.

Oku, S., Komatsu, A., Tajima, T., Nakashimada, Y., Kato, J., 2012. Identification of chemotaxis sensory proteins for amino acids in Pseudomonas fluorescens Pf0-1 and their involvement in chemotaxis to tomato root exudate and root colonization. Microb. Environ. 27 (4), 462-469.

O'toole, G.A., Kolter, R., 1998. Initiation of biofilm formation in Pseudomonas fluorescens WCS365 proceeds via multiple, convergent signalling pathways: a genetic analysis. Mol. Microbiol. 28 (3), 449-461.

Parker, J.K., Cruz, L.F., Evans, M.R., De La Fuente, L., 2015. Presence of calcium-binding motifs in PilY1 homologs correlates with Ca-mediated twitching motility and evolutionary history across diverse bacteria. FEMS Microbiol. Lett. 362 (4), 1-9.

Patrauchan, M.A., Sarkisova, S.A., Franklin, M.J., 2007. Strain-specific proteome responses of Pseudomonas aeruginosa to biofilm-associated growth and to calcium. Microbiology 153 (11), 3838-3851.

Périamé, M., Philippe, N., Condell, O., Fanning, S., Davin-Regli, A., 2015. Phenotypic changes contributing to Enterobacter gergoviae biocide resistance. Lett. Appl. Microbiol. 61 (2), 121-129.

Reinhold-Hurek, B., Hurek, T., 2011. Living inside plants: bacterial endophytes. Curr Op Plant Biol 14 (4), 435-443.

Rinaudi, L., Fujishige, N.A., Hirsch, A.M., Banchio, E., Zorreguieta, A., Giordano, W., 2006. Effects of nutritional and environmental conditions on Sinorhizobium meliloti biofilm formation. Res. Microbiol. 157 (9), 867-875.

Rodríguez, H., Fraga, R., Gonzalez, T., Bashan, Y., 2006. Genetics of phosphate solubilization and its potential applications for improving plant growth-promoting bacteria. Plant Soil 287, 15-21.

Romanova, Y.M., Smirnova, T.A., Andreev, A.L., Il'Ina, T.S., Didenko, L.V., Gintsburg, A. L., 2006. Formation of biofilms as an example of the social behavior of bacteria Microbiology 75 (4), 481-485.
Rotcheewaphan, S., Belisle, J.T., Webb, K.J., Kim, H.J., Spencer, J.S., Borlee, B.R., 2016. Diguanylate cyclase activity of the Mycobacterium leprae T cell antigen ML1419c. Microbiology 162 (9), 1651-1661.

Saharan, B.S., Nehra, V., 2011. Plant growth promoting rhizobacteria: a critical review. Life Sci. Med. Res. 21, 1-30.

Sauer, K., Camper, A.K., Ehrlich, G.D., Costerton, J.W., Davies, D.G., 2002. Pseudomonas aeruginosa displays multiple phenotypes during development as a biofilm. J. Bacteriol. 184 (4), 1140-1154.

Scharf, B.E., Hynes, M.F., Alexandre, G.M., 2016. Chemotaxis signaling systems in model beneficial plant-bacteria associations. Plant Mol. Biol. 90 (6), 549-559.

Schroth, M.N., Hancock, J.G., 1982. Disease-suppressive soil and root-colonizing bacteria. Science 216 (4553), 1376-1381.

Somasegaran, P., Hoben, H.J., 1994. Handbook for Rhizobia: Methods in LegumeRhizobium Technology, pp. 3-6. Section1.

Taurian, T., Anzuay, M.S., Angelini, J.G., Tonelli, M.L., Ludueña, L.M., Pena, D., Ibañez, F., Fabra, A., 2010. Phosphate-solubilizing peanut associated bacteria: screening for plant growth-promoting activities. Plant Soil 329 (1-2), 421-431.

Timmusk, S., Nevo, E., 2011. Plant root associated biofilms: perspectives for natural product mining. In: Bacteria in Agrobiology: Plant Nutrient Management. Springer, Berlin, Heidelberg, pp. 285-300.

Tomada, S., Puopolo, G., Perazzolli, M., Musetti, R., Loi, N., Pertot, I., 2016. Pea broth enhances the biocontrol efficacy of Lysobacter capsici AZ78 by triggering cell Motility Associated with Biogenesis of Type IV Pilus. Front. Microbiol. 7, 1-14.

Webb, B.A., Helm, R.F., Scharf, B.E., 2016. Contribution of individual chemoreceptors to Sinorhizobium meliloti chemotaxis towards amino acids of host and nonhost seed exudates. MPMI (Mol. Plant-Microbe Interact.) 29 (3), 231-239.

Weller, D.M., Thomashow, L.S., 1994. Current challenges in introducing beneficial microorganisms into the rhizosphere. In: O'Gara, Dowling, Boesten (Eds.), Molecular Ecology of Rhizosphere Microorganisms: Biotechnology and the Release of GMOs. VCH, Weinheim, pp. 1-18.

Whipps, J.M., 2001. Microbial interactions and biocontrol in the rhizosphere. J. Exp. Bot. 52 (Suppl. 1), 487-511.

Yao, J., Allen, C., 2006. Chemotaxis is required for virulence and competitive fitness of the bacterial wilt pathogen Ralstonia solanacearum. J. Bacteriol. 188 (10), 3697-3708.

Yaryura, P.M., León, M., Correa, O.S., Kerber, N.L., Pucheu, N.L., García, A.F., 2008. Assessment of the role of chemotaxis and biofilm formation as requirements for colonization of roots and seeds of soybean plants by Bacillus amyloliquefaciens BNM339. Curr. Microbiol. 56 (6), 625-632.

Zhalnina, K., Louie, K.B., Hao, Z., Mansoori, N., da Rocha, U.N., Shi, S., et al., 2018. Dynamic root exudate chemistry and microbial substrate preferences drive patterns in rhizosphere microbial community assembly. Nat Microbiol 3, 470-480.

Zhou, G., Li, L.J., Shi, Q.S., Ouyang, Y.S., Chen, Y.B., Hu, W.F., 2014. Efficacy of metal ions and isothiazolones in inhibiting Enterobacter cloacae BF-17 biofilm formation. Can. J. Microbiol. 60 (1), 5-14. 